\title{
Dielectric Constant of Compressed Gaseous and Liquid Oxygen*
}

\author{
B. A. Younglove** \\ Institute for Basic Standards, National Bureau of Standards, Boulder, Colorado 80302
}

(August 25, 1971)

\begin{abstract}
The dielectric constants of compressed gaseous and liquid oxygen were measured on ten isotherms at temperatures between 100 and $300 \mathrm{~K}$ and on the saturated liquid boundary at temperatures between 55 and $154 \mathrm{~K}$. Densities ranged from 0.06 to $1.30 \mathrm{~g} / \mathrm{cm}^{3}$ at pressures up to $33 \mathrm{MN} / \mathrm{m}^{2}$. The dielectric constant measurements were combined with accurate density data to compute the ClausiusMossotti (CM) function, $\left(\frac{\epsilon-1}{\epsilon+2}\right) \frac{1}{\rho}$. The CM function for oxygen decreases with density from a value
\end{abstract} of $0.1236 \mathrm{~cm}^{3} / \mathrm{g}$ at the low density limit to $0.1219 \mathrm{~cm}^{3} / \mathrm{g}$ near the triple point.

Key words: Clausius-Mossotti function; dielectric constant; oxygen.

\section{Introduction}

Very precise measurements of the dielectric constants of compressed gases and liquids, in principle, can give important information about the nature of molecular interactions. Also, density metering of fluids can be performed accurately and quickly by capacitance measurements when the dielectric constant as a function of density is known. Although such measurements have been reported for a number of simple fluids [1-6], ${ }^{1}$ no accurate wide-range measurements of compressed oxygen have yet been reported. This paper presents accurate dielectric constant measurements and derived values of the Clausius-Mossotti function $\left(\frac{\epsilon-1}{\epsilon+2}\right) \frac{1}{\rho}$ for oxygen at pressures from the dilute gas to nearly three times the critical density and at temperatures between the triple point of the fluid $(54.35 \mathrm{~K})$ and $300 \mathrm{~K}$.

\section{Experimental Method}

The dielectric constant was determined from the ratio of the capacitance when the cell was filled with fluid to the capacitance of the evacuated cell. The capacitor is essentially two coaxial cylinders of copper with the ends bearing on a common surface with three point contact in order to obtain high stability. Once assembled, the capacitor reproduced its vacuum capacitance versus temperature curve to within 1

* This work was carried out at the National Bureau of Standards under the sponsorship of the National Aeronautics and Space Administration Contract Order Number W-12, 745. ${ }^{* *}$ Cryogenics Division, Properties of Cryogenic Fluids, National Bureau of Standards, Boulder, Colo. 80302 .

${ }^{1}$ Figures in brackets indicate the literature references at the end of this paper. part in $10^{5}$ after temperature cycling to $55 \mathrm{~K}$ and pressure cycling to $34 \mathrm{MN} / \mathrm{m}^{2}(\sim 5000 \mathrm{psi})$. A detailed description of the capacitor, as used here, is given in reference [7].

The capacitance was measured with a commercial three-terminal a-c bridge, using tapped transformer windings in the ratio arms. The outer cylinder was operated at $10 \mathrm{~V}$ and $5 \mathrm{kHz}$, and the inner cylinder was connected to the detector side of the bridge. The bearing surfaces, sample holder, and outer conductor of the coaxial leads, and the bridge shield were grounded to form the third lead in the usual threeterminal connection for capacitance measurements.

\subsection{Cryostat}

The cryostat was all-metal construction, using liquid nitrogen as the refrigerant. The design is essentially that of Goodwin [8].

\subsection{Sample Holder and Sample}

The sample holder was made of electrolytic tough pitch copper. The sample temperature was regulated by nulling the platinum resistance thermometer emf against a fixed setting on a six dial potentiometer. The guard ring temperature was regulated to the sample temperature using a copper versus gold-cobalt thermocouple in a power control loop.

The sample was laboratory grade oxygen whose impurities, according to the supplier's specifications, were $17 \mathrm{ppm}$ argon, $12 \mathrm{ppm}$ hydrocarbon, $11 \mathrm{ppm}$ krypton, $10 \mathrm{ppm}$ nitrogen, and $2 \mathrm{ppm}$ water. This would contribute less than 0.01 percent to the polarizability. Even so, the sample was further purified by passing it through a silica gel trap at $77 \mathrm{~K}$. 


\subsection{Temperature, Pressure, and Density Measurements}

The temperature was measured with a $25 \Omega$ platinum resistance thermometer calibrated on the NBS-1955 and IPTS 1948 by the NBS Temperature Section. Adjustment to the IPTS 1968 can be made via reference [9]. The difference in CM, which results from neglecting the difference in the 1968 and 1948 scale, is small, usually much less than 0.2 percent. The calibration of the thermometer was checked periodically by measuring the vapor pressures of oxygen. The temperatures calculated from the vapor pressure measurements, using the tables of Weber [10], were within 4 millidegrees of that indicated by the thermometer calibration. Pressure measurements were made with a deadweight gage which communicates with the sample holder through a $0.056 \mathrm{~cm}$ i.d. stainless-steel capillary. Sensitivity of the pressure measurements were of the order of $10^{-4} \mathrm{MN} / \mathrm{m}^{2}$; the accuracy uncertainty was about twice that of the sensitivity.

The fluid densities were determined from temperature and pressure measurements and the PVT surface of Weber [10]. Uncertainties in the densities were believed to be less than 1 part in 1000 , except when within a few degrees of the critical temperature.
Near the critical point the densities may be in error by as much as 1 or 2 percent.

TABLE 1. Coefficients of Eqs (1) and (2)

\begin{tabular}{lrr|cl}
\hline \hline & \multicolumn{2}{c|}{ Eq. (1) } & \multicolumn{2}{c}{ Eq. (2) } \\
\hline$A$ & 0.12361 & (1) $\mathrm{cm}^{3} / \mathrm{g}$ & 0.12378 & $(2) \mathrm{cm}^{3} / \mathrm{g}$ \\
$B$ & .00032 & $(4) \mathrm{cm}^{6} / \mathrm{g}^{2}$ & .00029 & $(3) \mathrm{cm}^{6} / \mathrm{g}^{2}$ \\
$C$ & -.00121 & $(3) \mathrm{cm}^{9} / \mathrm{g}^{3}$ & -.00126 & $(2) \mathrm{cm}^{9} / \mathrm{g}^{3}$ \\
$D$ & & & -.00000067 & $(9) \mathrm{cm}^{3} / \mathrm{g} \mathrm{K}$ \\
$\sigma$ & .000038 & $\mathrm{~cm}^{3} / \mathrm{g}$ & .000032 & $\mathrm{~cm}^{3} / \mathrm{g}$ \\
\hline
\end{tabular}

$A, B, C$, and $D$, are coefficients for eqs (1) and (2); numbers in parentheses are estimated imprecision in the last digit of the coefficients, $\sigma$ is the rms deviation.

\section{Results and Discussions}

Measurements of dielectric constant, $\epsilon$, in the compressed fluid as a function of pressure or density on isotherms, with the corresponding values of CM are listed in table 2.

Experimental values $\epsilon$ at saturation (previously reported [14]) are given in table 3 .

Table 2. Dielectric constant measurements and Clausius-Mossotti function of compressed fluid oxygen

The densities were calculated from reference [10], using pressure and temperature as entries.

\begin{tabular}{|c|c|c|c|c|c|c|c|c|c|}
\hline$\underset{\mathrm{g} / \mathrm{cm}^{3}}{\rho}$ & $\begin{array}{c}\mathrm{CM} \\
\mathrm{cm}^{3} / \mathrm{g}\end{array}$ & $\epsilon$ & $\begin{array}{l}T \\
\mathrm{~K}\end{array}$ & $\begin{array}{c}P \\
\mathrm{MN} / \mathrm{m}^{2}\end{array}$ & $\underset{\mathrm{g} / \mathrm{cm}^{3}}{\rho}$ & $\begin{array}{c}\mathrm{CM} \\
\mathrm{cm}^{3} / \mathrm{g}\end{array}$ & $\epsilon$ & $\begin{array}{l}T \\
\mathrm{~K}\end{array}$ & $\begin{array}{c}P \\
\mathrm{MN} / \mathrm{m}^{\mathrm{a}}\end{array}$ \\
\hline 0.11189 & 0.12359 & 1.04207 & 300.0 & 8.357 & .50289 & .12343 & 1.19854 & 240.0 & 26.930 \\
\hline .09715 & .12359 & 1.03646 & 300.0 & 7.285 & .46111 & .12346 & 1.18109 & 240.0 & 24.060 \\
\hline .08547 & .12361 & 1.03203 & 300.0 & 6.432 & .64417 & .12333 & 1.25891 & 220.0 & 32.381 \\
\hline .07743 & .12361 & 1.02899 & 300.0 & 5.842 & .59875 & .12334 & 1.23922 & 220.0 & 28.225 \\
\hline .06884 & .12361 & 1.02575 & 300.0 & 5.210 & .54679 & .12343 & 1.21712 & 220.0 & 24.416 \\
\hline .05944 & .12362 & 1.02221 & 300.0 & 4.514 & .50155 & .12347 & 1.19804 & 220.0 & 21.688 \\
\hline .05748 & .12362 & 1.02147 & 300.0 & 4.368 & .45605 & .12350 & 1.17904 & 220.0 & 19.348 \\
\hline .05057 & .12363 & 1.01887 & 300.0 & 3.853 & .41352 & .12353 & 1.16149 & 220.0 & 17.426 \\
\hline .42831 & .12344 & 1.16747 & 280.0 & 29.929 & .35296 & .12359 & 1.13683 & 220.0 & 14.975 \\
\hline .32336 & .12352 & 1.12481 & 280.0 & 21.660 & .30203 & .12360 & 1.11634 & 220.0 & 13.055 \\
\hline & & & & & .19101 & .12359 & 1.07253 & 220.0 & 8.893 \\
\hline .25453 & .12355 & 1.09740 & 280.0 & 16.934 & & & & & \\
\hline .19988 & .12357 & 1.07598 & 280.0 & 13.367 & .16248 & .12361 & 1.06149 & 220.0 & 7.760 \\
\hline .47979 & .12342 & 1.18883 & 260.0 & 30.045 & .14137 & .12363 & 1.05337 & 220.0 & 6.889 \\
\hline .44900 & .12343 & 1.17602 & 260.0 & 27.557 & .12719 & .12364 & 1.04793 & 220.0 & 6.287 \\
\hline .39978 & .12351 & 1.15583 & 260.0 & 23.972 & .10949 & .12365 & 1.04117 & 220.0 & 5.512 \\
\hline .35279 & .12354 & 1.13672 & 260.0 & 20.885 & .73510 & .12309 & 1.29846 & 200.0 & 32.977 \\
\hline .31750 & .12355 & 1.12249 & 260.0 & 18.720 & .69060 & .12325 & 1.27910 & 200.0 & 28.096 \\
\hline .25405 & .12360 & 1.09725 & 260.0 & 15.041 & .58556 & .12342 & 1.23370 & 200.0 & 20.355 \\
\hline .20062 & .12363 & 1.07630 & 260.0 & 12.042 & .52454 & .12348 & 1.20777 & 200.0 & 17.436 \\
\hline .13218 & .12362 & 1.04984 & 260.0 & 8.173 & .47881 & .12351 & 1.18856 & 200.0 & 15.704 \\
\hline .12154 & .12363 & 1.04577 & 260.0 & 7.558 & .42090 & .12356 & 1.16458 & 200.0 & 13.864 \\
\hline .10563 & .12366 & 1.03970 & 260.0 & 6.628 & .37127 & .12359 & 1.14428 & 200.0 & 12.473 \\
\hline .07741 & .12364 & 1.02899 & 260.0 & 4.943 & .31196 & .12360 & 1.12031 & 200.0 & 10.906 \\
\hline .05646 & .12364 & 1.02109 & 260.0 & 3.656 & .26489 & .12363 & 1.10157 & 200.0 & 9.662 \\
\hline .54269 & .12341 & 1.21535 & 240.0 & 30.066 & .23176 & .12355 & 1.08843 & 200.0 & 8.753 \\
\hline
\end{tabular}




\begin{tabular}{|c|c|c|c|c|c|c|c|c|c|}
\hline $\begin{array}{c}\rho \\
\mathrm{g} / \mathrm{cm}^{3}\end{array}$ & $\begin{array}{c}\mathrm{CM} \\
\mathrm{cm}^{3} / \mathrm{g}\end{array}$ & $\epsilon$ & $\begin{array}{l}T \\
\mathrm{k}\end{array}$ & $\underset{\mathrm{MN} / \mathrm{m}^{2}}{P}$ & $\begin{array}{c}\rho \\
\mathrm{g} / \mathrm{cm}^{3}\end{array}$ & $\begin{array}{c}\mathrm{CM} \\
\mathrm{cm}^{3} / \mathrm{g}\end{array}$ & $\epsilon$ & $\begin{array}{l}T \\
\mathrm{~K}\end{array}$ & $\stackrel{P}{\mathrm{MN} / \mathrm{m}^{\mathrm{a}}}$ \\
\hline 0.21411 & 0.12362 & 1.08156 & 200.0 & 8.249 & .09240 & .12363 & 1.03467 & 160.0 & 3.030 \\
\hline .17476 & .12365 & 1.06626 & 200.0 & 7.063 & .05678 & .12362 & 1.02121 & 160.0 & 2.044 \\
\hline .14312 & .12363 & 1.05404 & 200.0 & 6.028 & 1.00036 & .12260 & 1.41937 & 140.0 & 32.781 \\
\hline .15121 & .12364 & 1.05715 & 200.0 & 6.301 & 0.96157 & .12274 & 1.40146 & 140.0 & 22.396 \\
\hline .11825 & .12366 & 1.04452 & 200.0 & 5.153 & .95619 & .12276 & 1.39899 & 140.0 & 21.171 \\
\hline .09658 & .12369 & 1.03627 & 200.0 & 4.340 & .94614 & .12280 & 1.39438 & 140.0 & 19.011 \\
\hline .07901 & .12370 & 1.02961 & 200.0 & 3.643 & .93411 & .12284 & 1.38887 & 140.0 & 16.638 \\
\hline .06087 & .12371 & 1.02276 & 200.0 & 2.882 & .92091 & .12289 & 1.38282 & 140.0 & 14.281 \\
\hline .82534 & .12298 & 1.33888 & 180.0 & 33.059 & .90835 & .12292 & 1.37707 & 140.0 & 12.264 \\
\hline .90737 & .12281 & 1.37623 & 160.0 & 31.425 & .89131 & .12297 & 1.36928 & 140.0 & 9.852 \\
\hline .85543 & .12300 & 1.35278 & 160.0 & 22.265 & .87299 & .12302 & 1.36094 & 140.0 & 7.643 \\
\hline .83368 & .12306 & 1.34296 & 160.0 & 19.323 & .83125 & .12307 & 1.34187 & 140.0 & 3.910 \\
\hline .80273 & .12313 & 1.32903 & 160.0 & 15.907 & 1.06595 & .12249 & 1.45052 & 120.0 & 26.000 \\
\hline .75569 & .12321 & 1.30800 & 160.0 & 12.142 & 1.03038 & .12265 & 1.43397 & 120.0 & 14.194 \\
\hline .70663 & .12328 & 1.28629 & 160.0 & 9.608 & 1.02298 & .12267 & 1.43050 & 120.0 & 12.099 \\
\hline .65984 & .12336 & 1.26584 & 160.0 & 8.119 & 1.01174 & .12271 & 1.42523 & 120.0 & 9.136 \\
\hline .61350 & .12344 & 1.24582 & 160.0 & 7.237 & 1.00032 & .12274 & 1.41989 & 120.0 & 6.393 \\
\hline .55699 & .12350 & 1.22162 & 160.0 & 6.644 & 0.98732 & .12277 & 1.41380 & 120.0 & 3.579 \\
\hline .51907 & .12351 & 1.20551 & 160.0 & 6.418 & 1.11997 & .12242 & 1.47670 & 100.0 & 11.648 \\
\hline .40624 & .12358 & 1.15857 & 160.0 & 6.048 & 1.10948 & .12246 & 1.47171 & 100.0 & 7.287 \\
\hline .33530 & .12357 & 1.12968 & 160.0 & 5.835 & 1.10182 & .12249 & 1.46807 & 100.0 & 4.302 \\
\hline .29645 & .12364 & 1.11415 & 160.0 & 5.670 & 1.09418 & .12252 & 1.46443 & 100.0 & 1.490 \\
\hline .25265 & .12364 & 1.09673 & 160.0 & 5.405 & & & & & \\
\hline .19693 & .12366 & 1.07488 & 160.0 & 4.884 & & & & & \\
\hline .15111 & .12368 & 1.05714 & 160.0 & 4.239 & & & & & \\
\hline
\end{tabular}

TABLE 3. Dielectric constant of saturated liquid oxygen

The densities were calculated from reference [10] using temperature as an entry.

\begin{tabular}{c|c|c|c||c|c|c|c}
\hline \hline$T$ & $\begin{array}{c}\rho \\
\mathrm{g} / \mathrm{cm}^{3}\end{array}$ & $\epsilon$ & $\begin{array}{c}\mathrm{CM} \\
\mathrm{cm} / \mathrm{g}\end{array}$ & $\begin{array}{c}T \\
\mathrm{~K}\end{array}$ & $\begin{array}{c}\rho \\
\mathrm{g} / \mathrm{cm}^{3}\end{array}$ & $\epsilon$ & $\begin{array}{c}\mathrm{CM} \\
\mathrm{cm}^{3} / \mathrm{g}\end{array}$ \\
\hline 54.478 & 1.3066 & 1.56848 & 0.12192 & 114.000 & 1.0117 & 1.42522 & .12270 \\
55.000 & 1.3038 & 1.56740 & .12199 & 118.000 & .9869 & 1.41356 & .12276 \\
56.000 & 1.2993 & 1.56510 & .12199 & 120.000 & .9740 & 1.40751 & .12279 \\
62.000 & 1.2728 & 1.55178 & .12206 & 122.000 & .9607 & 1.40132 & .12282 \\
64.000 & 1.2638 & 1.54731 & .12209 & 124.000 & .9469 & 1.39488 & .12283 \\
& & & & & & & \\
68.000 & 1.2458 & 1.53835 & .12213 & 126.000 & .9327 & 1.38828 & .12286 \\
72.000 & 1.2276 & 1.52935 & .12218 & 128.000 & .9180 & 1.38152 & .12291 \\
76.000 & 1.2091 & 1.52026 & .12224 & 130.000 & .9026 & 1.37440 & .12293 \\
80.000 & 1.1903 & 1.51108 & .12229 & 134.000 & .8698 & 1.35939 & .12300 \\
84.000 & 1.1712 & 1.50179 & .12235 & 138.000 & .8333 & 1.34282 & .12306 \\
& & & & & & & \\
88.000 & 1.1518 & 1.49242 & .12242 & 142.000 & .7916 & 1.32400 & .12313 \\
92.000 & 1.1319 & 1.48272 & .12245 & 146.000 & .7416 & 1.30164 & .12320 \\
96.000 & 1.1116 & 1.47285 & .12249 & 148.000 & .7114 & 1.28828 & .12323 \\
100.000 & 1.0907 & 1.46280 & .12254 & 150.000 & .6755 & 1.27244 & .12325 \\
102.000 & 1.0800 & 1.45769 & .12256 & 152.000 & .6291 & 1.25206 & .12320 \\
& & & & & & & \\
104.000 & 1.0691 & 1.45250 & .12259 & 153.000 & .5980 & 1.23804 & .12294 \\
106.000 & 1.0581 & 1.44723 & .12261 & 153.500 & .5783 & 1.22904 & .12265 \\
108.000 & 1.0469 & 1.44188 & .12263 & 154.000 & .5533 & 1.21646 & .12163 \\
110.000 & 1.0354 & 1.43637 & .12264 & & & & \\
112.000 & 1.0237 & 1.43089 & .12268 & & & & \\
\hline
\end{tabular}


The Clausius-Mossotti function can be empirically represented by a polynomial in density,

$$
\mathrm{CM} \equiv\left(\frac{\epsilon-1}{\epsilon+2}\right) \frac{1}{\rho}=A+B \rho+C \rho^{2} .
$$

The rms deviation of our measurements from eq (1) is $3.8 \times 10^{-5} \mathrm{~cm}^{3} / \mathrm{g}$, or about 0.028 percent in CM.

The departures of the compressed liquid isotherms from the saturated liquid curve, although not large, are believed to be a real effect. An addition of a linear term in temperature accounts for them quite well, i.e.,

$$
\mathrm{CM}=A+B \rho+C \rho^{2}+D T
$$

The rms deviation of our measurements from eq $(2)^{2}$ is then $3.2 \times 10^{-5} \mathrm{~cm}^{3} / \mathrm{g}$ in $\mathrm{CM}$ (0.03 percent).

Equation (1) may be inverted mathematically to give density as a function of the dielectric constant, providing a practical way to determine accurate fluid densities from capacitance measurements.

The low density limit of CM, i.e., the constant $A$ of eq (1), is the polarizability of the isolated oxygen molecule. As yet this quantity has not been calculated theoretically. However, accurate dielectric constant measurements of Dunn [11] at standard temperature and pressure of $\mathrm{O}_{2}$ (at $\left.\rho=0.0013 \mathrm{~g} / \mathrm{cm}^{3}\right)$ allows a check. His data when converted to CM differ from our measurements by 0.14 percent. This should be the upper limit of the uncertainty in CM, since it occurs at low density where the uncertainty is largest.

The appearance of figure 1 suggests that the second dielectric virial coefficient $B$ might be negative. However, the overall fit of the data to eq (2) indicated that $B$ is positive though small. Negative values for $B$ have been found for $\mathrm{He}$ [4] and $\mathrm{Ne}$ [5], which have caused difficulties for the theorists. Levine and McQuarrie [12] point out that although the form of the correct theory for $B$ is known, due to lack of knowledge of how the polarizability of a pair of molecules vary as a function of their separation, the usual simplification was to assume a constant polarization which is asymptotically valid in the limit of large separation. The result is that the predicted values of $B$ are always positive. Other words of discouragement have been expressed by Jansen [13]. He attempted to account for the density variations of the dielectric constant from a quantum mechanical basis, starting from the Lorenz microscopic field equations with the concept of a local field. He concludes that such a theory is fundamentally ineffective in accounting for the experimental results within their accuracy, even at low densities.

\footnotetext{
${ }^{2}$ The coefficients are given in table 1 .
}

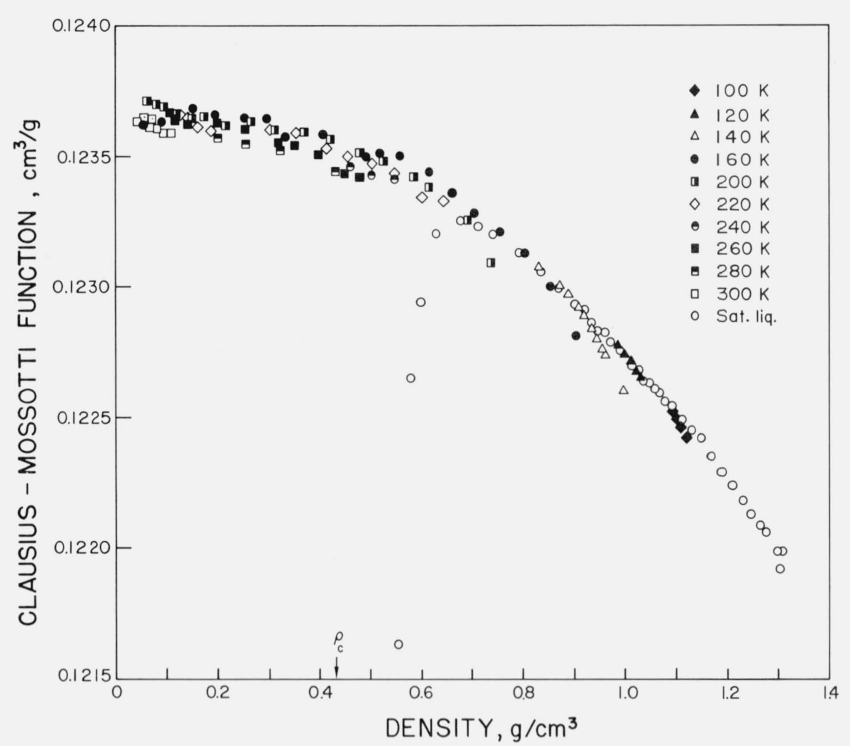

FigURE 1. CM function versus density for oxygen.

The author expresses appreciation and acknowledgement to G. C. Straty for suggestions concerning the capacitor design, and to D. E. Diller and L. A. Weber for their assistance.

\section{References}

[1] Michels, A., and Kleerekoper, L., Physica 6, 586 (1939), Michels, A., Lebesque, H. L., and de Groot, S. R., Physica 13, 337 (1947); Michels, A., and Botzen, L., Physica 15, 769 (1949).

[2] van Itterbeek, A., and Saepen, J., Physica 10, 173 (1943).

[3] Jones, G. O., and Smith, B. L., Phil. Mag. 5, 355 (1960).

[4] Johnson, D. R., Oudemans, G. J., and Cole, R. H., J. Chem. Phys. 33, 1310 (1960).

[5] Amey, R. L., and Cole, R. H., J. Chem. Phys. 40, 146 (1964); Orcutt, R. H., and Cole, R. H., Physica 31, 1779 (1965); Orcutt, R. H., and Cole, R. H., J. Chem. Phys. 46, 697 (1967).

[6] Stewart, J. W., J. Chem. Phys. 40, 3297 (1964).

[7] Younglove, B. A., and Straty, G. C., Rev. Sci. Inst. 41, 1087 (1970).

[8] Goodwin, R. D., J. Res. Nat. Bur. Stand. (U.S.) 65C (Eng. and Instr.) No. 4, 231-243 (1961).

[9] These temperatures may be converted to the IPTS 1968 from tables in Metrologia 35, 5 (1969); see table on page 44, and Metrologia 47, 5 (1969), see table on page 48.

[10] Weber, L. A., J. Res. Nat. Bur. Stand. (U.S.) 74A (Phys. and Chem.) No. 1, 93-130 (1970).

[11] Dunn, A. F., Canad. J. Phys. 42, 53 (1964).

[12] Levine, H. B., and McQuarrie, D. A., J. Chem. Phys. 49, 4181 (1968).

[13] Jansen, L., Phys. Rev. 112, 434 (1958).

[14] Younglove, B. A., Advances in Cryogenic Engineering Vol. 15, (Plenum Press, N.Y., 1970), p. 70.

(Paper 76Al-696) 